\title{
Working
}

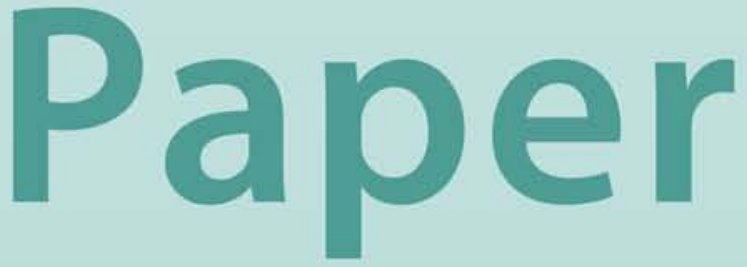




\section{The Efficiency of the Japanese Equity Market}

Jun Nagayasu 


\title{
IMF Working Paper
}

\author{
Statistics Department
}

\section{The Efficiency of the Japanese Equity Market}

\author{
Prepared by Jun Nagayasu ${ }^{1}$
}

Authorized for distribution by J. R. Rosales

July 2003

\begin{abstract}
The views expressed in this Working Paper are those of the author(s) and do not necessarily represent those of the IMF or IMF policy. Working Papers describe research in progress by the author(s) and are published to elicit comments and to further debate.
\end{abstract}

Using the ARFIMA-FIGARCH model, this paper studies the efficiency of the Japanese equity market by examining the statistical properties of the return and volatility of the Nikkei 225. It shows that both follow a long range dependence, which stands against the efficient market hypothesis $(\mathrm{EMH})$. The result is valid for all sample periods, suggesting that the recent equity market reform has not produced major efficiency gains.

\section{JEL Classification Numbers: G1}

Keywords:Nikkei 225, AFRIMA, ARFIMA-FIGARCH

Author’s E-Mail Address:Inagayasu@imf.org

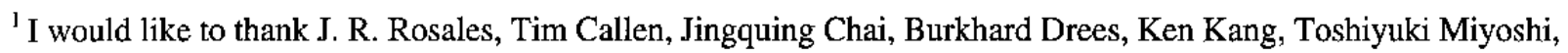
Kazunari Ohashi, and Toshitaka Sekine for useful comments on an earlier version. However, all errors are mine. The views presented here are mine and do not necessarily reflect those of the IMF or its policies. This paper will be published, in somewhat different form, in International Finance Review.
} 


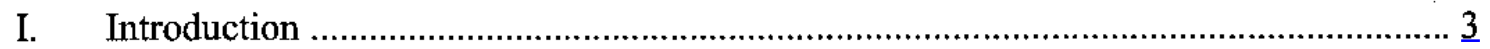

II. The Deregulation and Liberalization of the Japanese Equity Market: A Summary ....... 4

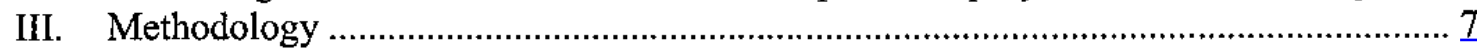

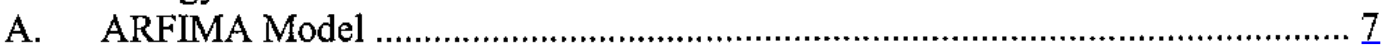

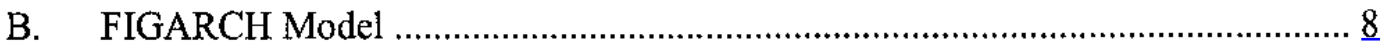

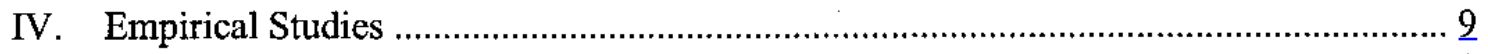

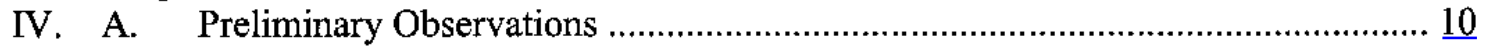

B. Results from the GARCH Type Models …................................................... 11

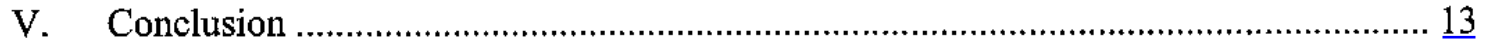

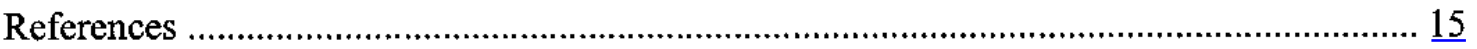

Tables

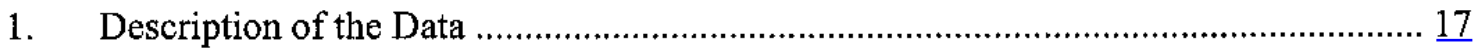

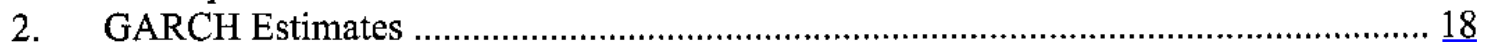

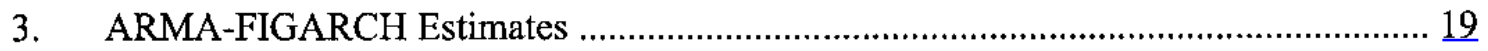

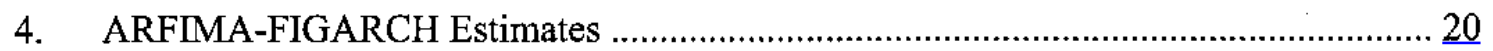

Figure

1. Daily Nikkei 225 from 1990/1/1-2002/8/8 ............................................................ 21

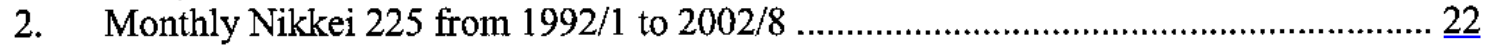




\section{INTRODUCTION}

Long-range dependence (or long memory) in equity data has important implications for the theoretical explanation of equity behavior. The efficient market hypothesis (EMH) provides probably the most popular explanation of the dynamics of equity data. Among several available definitions of market efficiency, Bachelier (1900) put forward a random walk version of the EMH that was formalized by Osborne (1959) and Fama (1965). It asserts that all past information that is useful for predictive purposes is contained in the most recent data $\left(P_{f}\right)$, and therefore, past equity data do not include any extra information that would improve forecast accuracy (i.e., $E\left[P_{t+1} \mid P_{t}, P_{t-1}, \cdots\right]=P_{t}$ ). Furthermore, the random walk process of equity prices implies that equity returns are stationary and can be expressed as ARIMA $(m, d$, $n$ ) where $d=0$. It therefore follows that long-range dependent equity return data $(d \neq 0)$ provide evidence of the existence of market inefficiency, and that data from the past contain useful information to improve the accuracy of the forecast. ${ }^{2}$

In order to test long-range dependence in equity data, previous research has used several statistical methods such as the Hurst-Mandelbrot rescaled range (R/S) statistics modified by Lo (1991) and/or the Auto-Regressive Fractionally Integrated Moving Average (ARFIMA) model. These methods have been applied to equity returns to test the null hypothesis of $d=0$, with very mixed results.

There are a number of studies that present evidence against long-range dependence in equity data. For example, such an indication has been provided by Lo (1991) using daily and monthly US equity returns (1962-1987), by Mills (1993) examining monthly UK stock returns from 1965-1990, and by Resende and Teixeira (2002) using the Brazilian stock market index (Ibovespa) around the period of the Real Stabilization Plan. Similarly, using the modified R/S test, Cheung and Lai (1995) have conducted a comprehensive study that includes monthly Morgan Stanley Capital International indices of 18 industrialized countries from 1970-1992, and that did not confirm the existence of long memory.

In contrast, there is evidence of long-range dependence in equity data. This has been reported for Austria, Italy, Japan, and Spain (Cheung and Lai 1995) using the ARFIMA method, for monthly Australian stock market returns from 1876-1996 (McKenzie 2001), for China (Lee et al 2001), and for weekly Greek stock data (ASE30) (Barkoulas et al 2000). Similarly, Sadique and Silvapulle (2001) report that Korean, Malaysian, New Zealand, and Singaporean data exhibit long memory in their seven country study of the period 1983-1998.

\footnotetext{
${ }^{2}$ Lo (1991) summarizes the difficulty in measuring market efficiency and proposes that ideally one should test it in the context of an equilibrium model that defines normal asset returns. The other implication of this EMH is that equity prices in less developed markets would be expected to exhibit a long memory because of the shallowness of their markets with less mature institutional and regulatory settings.
} 
In addition, Barkoulas et al (2000) show that forecasts from the ARFIMA model are more accurate than those from the random walk model.

Against this background, this paper examines the memory properties of equity returns and volatility using Nikkei 225 data in order to assess the efficiency of the Japanese equity market. We employ the concept of a martingale (Fama 1965) since existing statistical methods are readily applicable to this EMH concept, and many modern financial theories and empirical studies rely on this concept. As will be discussed later, a martingale version of the $\mathrm{EMH}$ is less restrictive than a random walk counterpart since it can allow time-varying volatility.

Our study makes a contribution to the existing literature in the following ways. First of all, our data sample includes more recent observations (up to 2002) than in previous studies. This is very important because the major deregulation of the Japanese market took place from 1997 onwards. Secondly, in view of the presence of volatility in many high frequency financial data (Peters 1996), we model simultaneously persistence in both equity returns and volatility using several time-series techniques including the Autoregressive Fractionally Integrated Moving Average (ARFIMA)-Fractionally Integrated General Autoregressive Conditional Heteroschedasticity (FIGARCH) model. The allowance of possible long-range dependence in equity returns and volatility is a relatively new concept. ${ }^{3}$ Based on our empirical results, we conclude that it is important to model long-range persistence in equity data. Furthermore, we argue that the equity market remains inefficient despite recent implementation of financial market reforms.

\section{The Deregulation and Liberalization of the Japanese Equity Market: A SUMMARY}

Prior to formal analysis, this section summarizes the institutional and regulatory features of the Japanese equity market. ${ }^{4}$ The pace of Japanese financial market reform has generally been slower than that of other industrialized countries, notably the UK and the US. Furthermore, equity market reforms used to lag far behind the pace of deregulation and liberalization of other domestic capital markets such as the bond and money markets (Hoshi and Kashyap 2001). ${ }^{5}$

\footnotetext{
${ }^{3}$ Crato and de Lima (1994) use FIGARCH and underline the persistence in the conditional variance of US stock data, such as the NYSE and S\&P500, from 1966-1991.

${ }^{4}$ Hirata (1999) argues that the unique characteristics of institutions and regulations have affected the capital structure of Japanese firms.

${ }^{5}$ See Hall (1998) for a summary of the deregulation and liberalization of the Japanese financial market. This slow process is in stark contrast to the urgent need for reform. Along with external pressure to internationalize the Japanese market, there was a demand for financial market reform in Japan. The first oil shock forced
} 
A December 1980 amendment to the Foreign Exchange and Foreign Trade Control Law of 1947, which liberalized cross-border transactions, has frequently been viewed as the turning point for the acceleration of financial reform in Japan. However, no major reform was implemented in the Tokyo Stock Exchange until the 1990s. ${ }^{6}$ Among many other measures implemented, a rule concerning new equity issuance, initially imposed by large securities firms in 1973, was abandoned in 1996. This rule specified strict conditions concerning the first issuance of company equities such as 1) company dividends had to be greater than 5 yen per stock in the previous year, 2) ordinary company profits should be greater than 10 yen per stock in the previous year, and 3) ordinary profits were expected to rise after issuance of a new stock (Hirota 1999). As a result, financing through issuance of new stock did not increase as rapidly as other financing methods such as convertible and warrant bonds.

Furthermore, in light of Tokyo's shrinking share of the global equity market and the prolonged domestic recession in the 1990s, the Japanese government under the Hashimoto administration announced in November 1996 a comprehensive reform scheme (the so-called Big Bang) to make the Japanese financial market transparent and internationally competitive, and bring the accounting and supervisory systems in line with international standards. ${ }^{7}$ While this scheme was multi-dimensional ranging from legal to institutional settings and from the banking to non-banking sectors, some reforms were aimed at improving the structure of the equity market. In particular, the ad valorem brokerage commission system introduced in April 1977 was initially relaxed for commissions on equity transactions of over Y1 billion. Furthermore, from April 1988, commissions on equity transactions of over Y50 million were freely determined, and in October 1999, all transactions were liberalized. From 1998, derivatives and options on individual stocks were allowed to be traded over-the-counter, and households were able to purchase equity mutual funds from banks. The 5:3:3:2 rule, which required that pension fund managers limit stock holdings to 30 percent or less, was abolished

domestic corporations to curtail investment and change their financing methods from bank loans to an increased reliance on capital markets. Similarly, high inflation caused by the oil shock motivated households to seek nontraditional assets with higher returns.

${ }^{6}$ Some progress was also made in the 1980 s. For example, prior to December 1985 , securities affiliates of foreign banks were not allowed to open branches in Japan because Article 65 of the Securities and Exchange Law separated the banking and securities business. Furthermorc, the Tokyo Stock Exchange (TSE) decided in 1985 to allow foreign securities companies to obtain membership, for the first time since its establishment in 1878 .

${ }^{7}$ The Big Bang was targeted to cover all financial institutions in contrast to the British Big-Bang that was confined to securities-related reforms. The Financial Supervisory Agency, which is responsible for the inspection and supervision of financial institutions and surveillance of security transactions, was established in June 1998. In July 2000, the agency was reorganized and renamed as the Financial Services Agency under the Financial Reconstruction Commission. 
in 1998. Banks were allowed to engage in all aspects of the securities business through their own subsidiaries in 1999.

In addition, following the Big Bang, involvement of foreign investors in the Japanese equity market increased considerably. The share of foreign equity ownership rose from 4 percent in 1989 to 19 percent in 2001, and is now higher than that in Germany or the U.S. In addition, overseas investors accounted for over 50 percent of annual turnover in 2001, up from 13 percent in 1989. With the increased presence of foreign investors in the equity market, one would expect market efficiency to have improved.

However, there are several economic factors that could help explain why the EMH appears not to hold in Japan. One factor is related to the so-called cross-shareholdings among Japanese corporations. The main banks and non-financial corporations in Japan have traditionally attempted to establish a strong and stable business relationship by holding stocks of partner institutions, which strengthens stock prices. Since FY 1990 however, crossshareholding generally appears to have declined in terms of the cross-shareholding ratio, defined as the ratio of cross-held shares versus all listed shares, which fell from more than 10 percent in FY1990 to 8.9 percent in FY2001. Furthermore, the unwinding of cross shareholding has recently accelerated on account of the introduction of mark-to-market accounting in 2001 (Kuroki 2002).

The other potential factor that may favor price movements inconsistent with the EMH is the Price Keeping Operations (PKO) conducted by the government. The PKO refer to the government's purchase of Japanese equities in order to prevent their prices from falling further, and this is frequently reported to have been implemented since 1992 . The funding for these operations has been provided by the Ministry of Public Management, Home Affairs, Posts and Telecommunications as well as the Government Pension Investment Fund (previously known as the Pension Welfare Service Public Corporation Organization). The timing of the purchase of the shares is determined by the Ministry of Finance, while the actual operations have been carried out by trust companies. Since the government's motivation here is not necessarily based purely on market conditions, the PKO likely erode market pricing and thus work against the EMH.

Finally, the restrictions on short-selling (kara-uri) may also have reduced market efficiency. These restrictions were originally introduced through enactment of the Securities Exchange Law in 1948, and were revised in March 2002. As a result of the revision, the Japan Cabinet Office ordinance clearly exempts certain types of transactions, including stock futures trading, as well as arbitrage and hedging transactions on stock price index futures and equity options trading. Among other effects, these restrictions in theory could reduce the liquidity of block trading and thus deprive traders of an important instrument to hedge large equity positions. However, this study does not fully capture the effect of this restriction since our dataset contains observations only through August 2002. 
The general perception, therefore, is that the Japanese market is now more consistent with the EMH concept than in the 1970s and 80s. In light of the deregulation and liberalization of the equity market that took place mainly from 1997 onwards, formal analysis would be expected to find evidence that the market has become more efficient over time.

\section{Methodology}

This paper studies the efficiency of the Japanese market using the martingale criterion. The stochastic process of an equity price $\left(P_{t}\right)$ follows a martingale process if $E\left[P_{t+1}-P_{t} \mid P_{t}, P_{t-1}, \cdots\right]=0$. This is equivalent to saying that price changes are unpredictable. In other words, when the time-series property of equity returns is expressed as $\operatorname{ARIMA}(m, d, n)$, the hypothesis of whether equity returns follow the EMH or not can be tested by analyzing the size of its differencing parameter, $d$. When $d=0$, evidence is provided to support the $\mathrm{EMH}$, but $d \neq 0$ rejects the concept. The other important property of the martingale process is that the conditional variance of price changes is predictable from the past variance (Cuthbertson 1996). This feature of the martingale model distinguishes itself from the random walk model where the variance should be time-invariant. In order to carry out this test, we use the time-series method that allows us to estimate the long-range dependence of the data; namely, the ARFIMA-FIGARCH model. This section summarizes the ideas behind the ARFIMA, which is an extension of the ARIMA, and the FIGARCH model that has been developed to capture long-range dependence in equity volatility.

\section{A. ARFIMA Model}

Granger and Joyeux (1979) and Hosking (1981) developed the ARFIMA model that is often used to analyze long-range dependency in financial assets. As discussed, this method has been frequently used in order to test the efficiency of financial markets. The general specification of this model, ARFIMA $(m, d, n)$, can be expressed as:

$$
\phi(L)(1-L)^{d} y_{t}=\theta(L) \varepsilon_{t}
$$

The $L$ is a lag operator, and $\phi(L)=1-\sum_{j=1}^{m} \phi_{j} L^{j}$ and $\theta(L)=1+\sum_{j=1}^{n} \theta_{j} L^{l}$. All the roots of $\phi(L)$ and $\theta(L)$ lie outside the unit circle. The residual, $\varepsilon_{t}$, is white noise with a variance, $\sigma^{2}$. The fractional differencing parameter, $d$, measures the level of integration of the equity index data, i.e., $y_{t} \sim I(d)$, and the fractional differencing operator $(1-L)^{d}$ can be defined as:

$$
(1-d)^{d}=\sum_{j=0}^{\infty} \frac{\Gamma(j-d) L^{j}}{\Gamma(-d) \Gamma(j+1)}
$$

where $\Gamma(\cdot)$ is the gamma function. Process (1) may possess a long memory such that a shock at time $t$ has a long-lasting influence on the future value of the time-series compared with the case of a stationary ARIMA (i.e., $d=0$ and $y_{1}$ is white noise) whose autocorrelation function exponentially converges to zero $\left(\rho_{j}=c \theta^{\prime}\right.$ with $\left.|\theta|<0\right)$. The long-memory process 
emerges because $d$ no longer needs to be an integer. For ARFIMA $(0, d, 0)$ and $d \in(-0.5,0.5)$, the process $y_{1}$ is weakly stationary and invertible. When $d<0.5$ and $d \neq 0$, the autocorrelation function of the time-series can be simplified to $\rho_{j} \approx c j^{2 d-1}$ as $j \rightarrow \infty$ where $c$ is the ratio of gamma functions, which indicates that the autocorrelation function hyperbolically converges to zero with speed dependent on the size of $d$ (Granger and Joyeux 1979 , Hosking 1981). Therefore, the speed of the convergent process for $d \in(-0.5,0.5)$ is slower than that of the white noise. Indeed, when $d \in(0,0.5)$, autocorrelations are positive and decay monotonically and hyperbolically to zero. The autocorrelations of the process with $d \in(-0.5,0)$ are all negative except $\rho_{0}=1$ and decay monotonically and hyperbolically to zero (Hosking 1981). ${ }^{8}$ Therefore, long-range dependence in equity data raise evidence against the EMH.

\section{B. FIGARCH Model}

The FIGARCH model has been developed by Baillie, Bollerslev, and Mikkelsen (1996), and relaxes the assumption of $\sigma^{2}$ used in equation (1). The general specification can be derived as an extension to the standard GARCH model that can be expressed as:

$$
h_{t}=\omega+\alpha(L) \varepsilon_{t}^{2}+\beta(L) h_{t}
$$

where $h$ and $\varepsilon_{t}^{2}$ are conditional and unconditional variances of $\varepsilon_{t}$ respectively, $\omega=\varepsilon^{2}[1-\beta(1)-\alpha(1)]$, and $\phi(L)=1-\sum_{j=1}^{q} \phi_{j} L^{j}$ and $\beta(L)=1+\sum_{j=1}^{p} \beta_{j} L^{j}$. Equation (5) can also be written as:

$$
[1-\alpha(L)-\beta(L)] \varepsilon_{t}^{2}=\omega[1-\beta(L)] v_{t}
$$

where $v_{t} \equiv \varepsilon_{t}^{2}-h_{t}^{2}$ with zero mean and serially uncorrelated, and $E_{t-1}\left(v_{t}\right)=0$. To be consistent with the covariance stationary process of $\varepsilon_{t}$, all the roots of $[1-\alpha(L)-\beta(L)]$ and $[1-\beta(L)]$ lie outside the unit circle. The general specification of the FIGARCH (Baillie, Bollerslev, and Mikkelsen 1996)) can be written by introducing the fractional differencing term in the conditional variance equation (4):

$$
\phi(L)(1-L)^{\bar{d}} \varepsilon_{t}^{2}=\omega+[1-\beta(L)] v_{t}
$$

The fractional differencing operator, $(1-L)^{\vec{d}}$, can also be expressed using the gamma function as in (2). Furthermore, $\bar{d} \in(0,1)$ and all the roots of $\phi(L)$ and $[1-\beta(L)]$ lie outside the unit circle. The FIGARCH encompasses other GARCH type models, and is equivalent to the GARCH when $\bar{d}=0$ and to the IGARCH when $\bar{d}=1$. Therefore, while $\bar{d}$ measures

\footnotetext{
${ }^{8}$ Mandelbrot (1977) calls the process with $\mathrm{d}<0$ as short memory or anti-persistent. However, since both the processes with $-0.5<d<0$ and $0<d<0.5$ exhibit a slower convergence than the stationary ARMA case, we call these series long-range persistent. The use of this terminology is consistent with Campbell, Lo, and MacKinlay (1997).
} 
long-range dependence in the FIGARCH model, the interpretation of the fractionally differencing term here is different from that of the ARFIMA in that the FIGARCH process may not be covariance stationary but strictly stationary and ergodic for $0 \leq \bar{d} \leq 1$ (Baillie, Bollerslev, and Mikkelsen 1996). Equation (5) can also be expressed as $[1-\beta(L)] h_{t}^{2}=$ $\omega+\left[1-\beta(L)-\phi(L)(1-L)^{\bar{d}}\right] \varepsilon_{\mathrm{t}}^{2}$, which can be simplified for the $\operatorname{FIGARCH}(1, \bar{d}, 1)$ as:

$$
h_{t}^{2}=\omega+\left[1-\left(1-\beta_{1} L\right)^{-1}\left(1-\phi_{1} L\right)(1-L)^{\bar{d}}\right] \varepsilon_{r}^{2}
$$

Baillie, Bollerslev, and Mikkelsen (1996) argue that the following are sufficient conditions to ensure a positive conditional variance of the $\operatorname{FIGARCH}(1, \bar{d}, 1) \operatorname{model}$ for all $t: \omega>0$, $0 \leq \bar{d} \leq 1-2 \phi_{1}$, and $0 \leq \beta_{1} \leq \phi_{1}+\bar{d}$.

The abovementioned models will be estimated by the maximum likelihood method. Existing studies have often estimated the size of $\bar{d}$ using a semi-parametric approach in the frequency domain (Geweke and Porter-Hudak (GPH) 1983, Robinson 1994). However, this method has a number of very serious deficiencies. While the semi-parametric estimator of GPH is potentially robust to non-normality, the estimates are adversely biased by the presence of autocorrelation (Agiakloglou, Newbold, and Wohar 1992). Similarly, Robinson's approach, which is based on the properties of a discretely averaged periodogram, suffers from discontinuity in the asymptotic distribution theory (see Baillie 1996). Thus, the maximum likelihood method, which maximizes the following log-likelihood, is employed:

$$
\begin{aligned}
\ell= & T\{\ln \Gamma[0.5(d f+1)]-\ln \Gamma(0.5 d f)-0.5 \ln [\pi(d f-2]\} \\
& -0.5 \sum_{t=1}^{T}\left\{\ln \left(h_{t}\right)+(1+d f) \ln \left[1+\varepsilon_{t}^{2} /\left(h_{t}[d f-2]\right)\right]\right\}
\end{aligned}
$$

where $d f$ represents the degrees of freedom. Following the results of previous findings that returns are not normally distributed, equation (7) assumes the Student $t$ distribution.

\section{EMPIRICAL STUDIES}

Our analysis is based on daily Nikkei 225 data from 1990/1/1 to 2002/8/8, which are obtained from Datastream. ${ }^{9}$ This data has probably been most frequently used to monitor stock market activities in Japan, and consists of the most actively traded (liquid) stocks on the first section of the Tokyo Stock Exchange (TSE) while taking into account the sectoral

\footnotetext{
${ }^{9}$ The overall conclusion reported in this section is still valid even when other major index data (JASDAQ and TOPIX) are used.
} 
distribution. ${ }^{10}$ The compilation method of this index resembles that used to calculate the Dow Jones. The Nikkei exhibits a declining trend with large fluctuations during this period (see Figure 1). The average price of 34,592 yen in 1990 became 26,409 yen in 1991 , and furthermore declined to 10,588 yen in 2002 . Similarly, the average total market value of the Nikkei fell by 14 percent between 1991 and 2002. This reduction in the market value seems due mainly to declining prices since the trading volume has shown an increasing trend since the early 1990 s.

In this paper, the equity return is defined as $\left(p_{t}-p_{t-1}\right) \times 100$, where $p_{t}$ is the log of the equity price at time $t$. In addition to this full period, our study analyzes a sub-sample $(1997 / 1 / 1-2002 / 8 / 8)$ in order to find the sensitivity of our result to sample periods. The cutoff point for this sub-sample is broadly consistent with the implementation of equity market reform. In other words, as discussed in the previous section, the post-1997 data should contain more information on equity behavior during a major deregulation period. Our paper utilizes daily data due to its relevance to market operations.

\section{A. Preliminary Observations}

Prior to formal analysis, Table 1 examines the time-series properties of individual data using basic methods, and generally confirms the findings of previous studies. The results of the Augmented Dicky-Fuller (ADF) unit root test offer evidence in favor of stationary equity returns. While this test may be deficient in terms of its ability to capture an order of integration that may not be an integer ${ }^{11}$, our findings of stationary equity returns are consistent with those of Lo (1991), Mills (1993), Resende and Teixeira (2002) as well as Cheung and Lai (1995) using the modified R/S test. However, based on the Jarque-Bera normality (1987) and Engle's Lagrange Multiplier ARCH (1982) tests, equity return data exhibit non-normality and ARCH effects. These results provide evidence against the market efficiency specified in the random walk version of the EMH.

In Section II, we discussed how the government's purchase of stocks (known as PKO) may be one factor contributing to the inefficiency of the Japanese equity market. It is generally believed that these operations were initiated in 1992 and were frequently conducted around the month of March when equity prices had declined earlier in the year (i.e., January

\footnotetext{
${ }^{10}$ The TSE domestic market is divided into two sections. Briefly, the first section is the market for stocks of larger companies, and the second is for those of smaller and newly listed companies with lower trading volume levels. TSE stocks are reviewed every year as regards whether they meet the criteria for the first or second sections. About 1,500 companies are listed in the first section, and more than 500 companies in the second one.

${ }^{11}$ Baillie (1996) summarizes the poor performance of unit root tests in the presence of long-range dependence in data.
} 
and/or February). ${ }^{12}$ For illustrative purposes, Figure 2 shows monthly Nikkei data for 19922002. While it is not feasible to judge whether the PKO alone were a reason for the changing trend in price movements, this figure indicates that there were several occasions in which either the direction or the speed of declining equity prices in the early years were changed or decelerated in March. However, it appears that the PKO generally had only a limited and temporary impact on equity prices.

\section{B. Results From The GARCH Type Models}

The non-white noise characteristics of equity data have motivated us to extend our model to take them into account in our statistical equity models. To this end, we have estimated the GARCH $(1,1)$ models using the assumption of the Student $t$ distribution. Table 2 confirms our previous findings on the importance of the non-normality and (G)ARCH effects by showing that the degree of freedom as well as the GARCH and ARCH terms are all statistically significant. It should be noted that the parameters of the conditional variance equations are all positive and statistically significant. Furthermore, they meet the positivity constraint for the GARCH $(1,1)$. This confirms the existence of the time-varying conditional variance, which can be interpreted as time-varying uncertainty among investors about equity movements. The models' appropriateness has also been checked by applying the Box-Pierce $Q$ statistic test to standardized and squared standardized residuals.

One drawback of the standard GARCH model is its inability to capture long-range dependence in data. Therefore, the $\operatorname{ARMA}(0,0)-\operatorname{FIGARCH}(1, \bar{d}, 1)$ model is employed in order to analyze the existence of possible long-range dependent volatility. ${ }^{13}$ Results from this model are shown in Table 3, and suggest that the fractional differencing parameters are significantly different from zero and are within the theoretical value (i.e., $0 \leq \bar{d} \leq 1$ ). While the size of the fractional differencing term is somewhat smaller during the more liberalized period (1997-2002), this result remains valid regardless of sample periods. It therefore confirms the importance of modeling long-range dependent volatility. This finding furthermore indicates that future volatility is a function of its past value and so is predictable from past information. Long-range dependent volatility does not violate the martingale model of the EMH, but the existence of the time-varying volatility itself raises evidence against market efficiency as defined by the random walk version.

\footnotetext{
${ }^{12}$ Detailed information related to the PKO has never been disclosed by the government, but the PKO frequently took place around March because many banks calculate the losses or gains from their equity holdings using March stock price data.

${ }^{13}$ Our analysis is based on $(1, d, 1)$ in order to use the positivity conditions attached to the FIGARCH term (see Section III.B).
} 
Furthermore, while evidence is obtained of asymmetric movements in the Nikkei 225 in the full sample period, such evidence is not observed in the sub-sample period that excludes old observations, which is consistent with Nagayasu (2002). In addition, many GARCH and ARCH terms, as well as all degrees of freedom, are statistically significant, confirming the time-varying variance and non-normality of the equity returns. These results are based on the models that capture well the data-generating process of the equity returns using the autocorrelation criterion.

Finally, we conduct a test to investigate market efficiency by examining the size of the fractional differencing parameter, $d$, in the mean equation. Given the significance of longrange dependent volatility, the $\operatorname{ARFIMA}(0, d, 0)-\operatorname{FIGARCH}(1, \vec{d}, l)$ model is employed. Table 4 summarizes our findings and suggests inefficiency in the Japanese equity market, regardless of the sample period. The size of $d$ ranges from -0.5 to 0.5 . Interestingly, the fractional differencing parameters, $d$, for the mean equations are negative, and the size of the parameter in this period is not statistically different from that in the full sample $(t=-0.842)$. This sign is different from previous studies (Cheung and Lai 1995) that include much older sample periods (i.e., the 1970s and 1980s), but is coherent with the data showing a generally declining trend during our sample period. As discussed, the sign of $d$ is consistent with the autocorrelation coefficients of the equity data. Therefore, the pronounced declining movement of equity price data in our period appears to have contributed to the negative sign of $d$. This significant size of $d$ underlines the importance of modeling the long-range dependence for the Nikkei data.

The result of $d \neq 0$ from these models is sharply in contrast to our findings from the unit root tests that led to a conclusion of $d=0$, and does not seem to be sensitive to the sample period. It follows that, despite our expectations from historical facts, the Japanese equity market remains inefficient. While further research is needed, several possible explanations for the inefficiency in the Japanese market can be posited. While we did not empirically investigate the causes of market inefficiency, a combination of several factors is discussed as contributing to this result. Graphical analysis indicates that the PKO seem to have some temporary effects, if any, on equity returns. Furthermore, the cross-shareholding ratio suggests that, although declining, this practice still continues between corporations. Financial dependency between corporations remains very high (about 30 percent of the overall market) when a more comprehensive indicator called the long-term shareholding ratio is used (Okabe 2001 and Kuroki 2002). ${ }^{14}$ More generally, a recent survey conducted by the Cabinet Office (2002) shows that individual investors are not responsive to the reform measures introduced since 1997. Indeed, about 83 percent of individual investors have indicated their intention not to participate in equity trading. These factors seem to go some way towards explaining why the equity market remains inefficient.

\footnotetext{
${ }^{14}$ The long-term shareholding ratio takes into account cross-shareholdings, noncross-shareholdings involved financial institutions, and shares held by listed affiliated companies (see Kuroki 2002).
} 
Similar to the mean equations, the fractional differencing terms $(\bar{d})$ of the conditional variance equations show the long-range dependency in volatility. Their values range from 0 to 1 , but they are significantly different from zero. The fact that conditional variance has a long memory process regardless of sample period indicates that time-varying uncertainty has remained an important factor in explaining daily Nikkei data. Volatility or uncertainty can arise from news, and therefore persistent uncertainty among investors may be explained by more frequent news due to the increased use of IT in the market. If indeed that is the case, volatility itself is unlikely to disappear in the future.

\section{Conclusion}

The efficiency of the Japanese equity market has been studied by examining the time series properties of the returns and volatility of the Nikkei 225 from 1990/1/1 to 2002/8/8. Our study differs in several respects from previous ones, most notably because it 1) analyzes a sample period which includes financial deregulation, and 2) estimates, using the maximum likelihood method, persistence in equity returns and volatility simultaneously. This was made possible by employing the ARFIMA-FIGARCH model.

We have obtained two interesting results. Using the efficient market hypothesis (i.e., adjustment speed measured by the fractionally differencing term) as a criterion, our study shows that equity returns are stationary with a convergence much slower than the stationary ARIMA (i.e., $d=0$ ) case. This result stands in marked contrast to those derived from the unit root tests. Based on these results, this paper concludes that the Japanese equity market does not conform to the efficient market hypothesis. More generally, this suggests that a theoretical equity model based on a standard stochastic movement in equity data may not have great relevance to the situation in Japan.

Furthermore, this paper presents evidence of long-range dependence in equity returns and volatility regardless of the sample period. This paper points to a number of possible factors behind the absence of improvements in market efficiency despite the recent reduction in legal restrictions in the Japanese equity market, which is now more comparable with that of other industrialized countries such as the UK. While declining in importance in recent years, corporate cross-shareholding and government efforts to prevent share prices from falling, are practices that likely hindered efficiency.

Finally, while our analysis is comprehensive as regards the Nikkei 225 , further analysis could usefully be conducted in a number of directions. One extension would be to investigate the exact causes of the inefficiencies in the Japanese equity market. This paper has proposed several possible explanations for future consideration. Another possibility would be to expand country coverage and compare our findings with those in equity markets in other countries. If evidence is found of long-range dependence in equity volatility in other 
cases, further close study of the causes of the persistent volatility could yield useful information. A third extension would be to use a statistical model that captures the asymmetric movements in equity data along the lines of Bollerslev and Mikkelson (1996). As in previous literature and our study, the equity data appear to respond heterogeneously to good and bad news in the full sample period. Our study did not touch on this issue because of the accompanying computational complications and the fact that such asymmetry issues did not occur in our equity data in the post-1997 period. 


\section{References}

Agiakloglou, C, P. Newbold, and M. Wohar, 1992, "Bias in an Estimator of the Fractional Difference Parameter," Journal of Time Series Analysis, Vol. 14, No. 3, pp. 235-46.

Bachelier, L., 1900. Theory of Speculation (Paris: Gauthier-Villars).

Baillie, Richard T., 1996, "Long Memory Processes and Fractional Integration in Econometrics," Journal of Econometrics, Vol. 73, No. 1, pp. 5-59.

Baillie, Richard T., Tim Bollerslev, and Hans Ole Mikkelsen, 1996, "Fractionally Integrated Generalized Autoregressive Conditional Heteroskedasticity," Journal of Econometrics, Vol. 74, No. 1, pp. 3-30.

Barkoulas, John T., Christopher F. Baum, Nickolaos Travlos, 2000, "Long Memory in the Greek Stock Market," Applied Financial Economics, Vol. 10, No. 2, pp. 177-84.

Bollerslev, Tim and Hans Ole Mikkelsen, 1996, "Modeling and Pricing Long Memory in Stock Market Volatility,” Journal of Econometrics, Vol. 73, No. 1, pp. 151-84.

Campbell, John Y., Andrew W. Lo, and A. Craig MacKinlay, 1997, The Econometrics of Financial Markets (Princeton: Princeton University Press).

Cheung, Yin-Wong, and Kon S. Lai, 1995, "A Search for Long Memory in International Stock Market Returns," Journal of International Money and Finance, Vol. 14, No. 4, pp. 597-615.

Cheung, Yin-Wong, Kon S. Lai, and Micahel Lai, 1993, "Are There Long Cycles in Foreign Stock Returns?" Journal of International Financial Markets, Institutions, Money, Vol. 3, No. 1, pp. 33-47.

Chow, K. Victor, Karen C. Denning, Stephen Ferris, and Gregory Noronha, 1995, "LongTerm and Short-Term Price Memory in the Stock Market," Economics Letters, Vol. 49, No. 3, pp. 287-93.

Crato, Nuno, and de Pedro J. F. de Lima, 1994, "Long-Range Dependence in the Conditional Variance of Stock Returns," Economics Letters, Vol. 45, No. 3, pp. 281-85.

Cuthbertson, Keith, 1996, Quantitative Financial Economics: Stocks, Bonds, and Foreign Exchange (New York: Wiley).

Dekle, Robert, 1998, "The Japanese 'Big Bang': Financial Reforms and Market Implications," Journal of Asian Economics, Vol. 9, No. 2, pp. 237-49.

Engle, Robert. F., 1982, "Autoregressive Conditional Heteroscedasticity with Estimates of the Variance of United Kingdom Inflation," Econometrica, Vol. 50, No. 4, pp. 987-1007.

Fama, Eugene. F., 1965. "The Behavior of Stock Market Prices," Journal of Business, Vol. 38, No. 1, pp. 34-105.

Geweke John and Susan Porter-Hudak, 1983, "The Estimation and Application of Long Memory Time Series Models," Journal of Time Series Analysis, Vol. 4, No. 4, pp. 221-38.

Granger, Clive. W. J. and Roselyne Joyeux, 1980, "An Introduction to Long-Memory Time Series Models and Fractional Differencing," Journal of Time Series Analysis, Vol. 1, No. 1, pp. 15-29.

Hall, Maximilian J. B., 1998, Financial Reform in Japan: Causes and Consequences (Cheltenham: Edward Elgar). 
Hirota, Shin'ichi, 1999, "Are Corporate Financing Decisions Different in Japan? An Empirical Study on Capital Structure," Journal of the Japanese and International Economies, Vol. 13, No. 3, pp. 201-29.

Hoshi, Takeo and Anil K. Kashyap, 2001, Corporate Financing and Governance in Japan (Cambridge: MIT Press).

Hosking, J. R. M., 1981, "Fractional Differencing," Biometrika, Vol. 1, No. 1, pp. 165-76.

Japan Cabinet Office, 2002. Opinion Survey on Securities Investment. (Tokyo: Japanese Cabinet Office).

Jarque, Carlos M. and Anil K. Bera, 1987, "A Test of Normality of Observations and Regression Residuals," International Statistical Review, Vol. 55, pp. 163-72.

Kuroki, Fumiaki, 2002, "Cross-Shareholdings Decline for the $11^{\text {th }}$ Straight Year (FY 2001 Survey)," Financial Research Group (Tokyo: NLI Research Institute)

Lee, Cheng F., Gong-meng Chen, and Oliver M. Rui, 2001, "Stock Retums and Volatility on China's Stock Markets," Journal of Financial Research, Vol. 24, No. 4, pp. 523-43.

Lo, Andrew W., 1991, "Long-Term Memory in Stock Market Prices," Econometrica, Vol. 59, No. 5, pp. 1279-313.

Lo, Andrew W., 1997, "Fat Tails, Long Memory, and the Stock Market since the 1960s," Economic Notes, Vol. 26, No. 2, pp. 213-46.

Mandelbrot, B. B., 1977, Fractals: Form, Chance and Dimension (San Francisco: Freeman).

McKenzie, Michael D., 2001, "Non-Periodic Australian Stock Market Cycles: Evidence from Rescaled Range Analysis," Economic Record, Vol. 77, No. 239, pp. 393-406.

Mills, Terence C., 1993, "Is There Long-Term Memory in UK Stock Returns?" Applied Financial Economics, Vol. 3, No. 4, pp. 303-6.

Nagayasu, Jun, 2002, "Equity Price and Volatility Spillover After the Asian Crisis: ARFIMA-GARCH" draft, August (Washington DC: International Monetary Fund).

Okabe, Mitsuaki, 2001, "Are Cross-Share Holdings of Japanese Corporations Dissolving? Evaluation and Implication," The Nissan Occasional Paper Series No. 33. (Oxford: Oxford University).

Osborne, M. F. M., 1959, "Brownian Motion in the Stock Market," Operations Research Vol. 7, pp. 145-73.

Peters, Edgar E., 1996. Chaos and Order in the Capital Market, $2^{\text {nd }}$ ed. (New York: John Wiley \& Sons, New).

Resende, Marcelo and Nilson Teixeira, 2002, "Permanent Structural Changes in the Brazilian Economy and Long Memory: A Stock Market Perspective," Applied Economic Letters, Vol. 9, No. 6, pp. 373-5.

Robinson, P. M., 1994, "Semiparametric Analysis of Long-Memory Time Series," The Annuals of Statistics, Vol. 22, No. 1, pp. 515-39.

Sadique, Shibley and Param Silvapulle, 2001, "Long-Term Memory in Stock Market Returns: International Evidence," International Journal of Finance and Economics, Vol. 6, No. 1, pp. 59-67. 
Table 1. Description of the Data

\begin{tabular}{|c|c|c|}
\hline No. of observations & & 3288 \\
\hline Mean & & -0.042 \\
\hline Standard Deviation & & 1.506 \\
\hline Skewness & & 0.268 \\
\hline Normality test & & $\mathrm{Chi}^{\wedge}(2)=780.69^{* *}$ \\
\hline $\mathrm{ARCH}(5)$ test & & $\mathrm{F}(5,3277)=32.62 * *$ \\
\hline $\mathrm{ARCH}(10)$ test & & $F(10,3267)=18.81 * *$ \\
\hline \multicolumn{3}{|l|}{ Unit root test } \\
\hline Lags & Constant & Constant/Trend \\
\hline 10 & $-16.33^{* *}$ & $-16.33 * *$ \\
\hline 9 & $-17.38 * *$ & $-17.38 * *$ \\
\hline 8 & $-18.60 * *$ & $-18.60 * *$ \\
\hline 7 & $-20.85 * *$ & $-20.85 * *$ \\
\hline 6 & $-22.71 * *$ & $-22.71^{* *}$ \\
\hline 5 & $-24.68 * *$ & $-24.68 * *$ \\
\hline 4 & $-26.38 * *$ & $-26.38 * *$ \\
\hline 3 & $-29.50^{* *}$ & $-29.49 * *$ \\
\hline 2 & $-34.71^{* *}$ & $-34.71 * *$ \\
\hline 1 & $-43.67 * *$ & $-43.67 * *$ \\
\hline 0 & $-58.78 * *$ & $-58.77^{* *}$ \\
\hline
\end{tabular}


Table 2. GARCH Estimates

\begin{tabular}{l|cc}
\hline & $1990 / 1 / 1-2002 / 8 / 8$ & $1997 / 1 / 1-2002 / 8 / 8$ \\
\hline Constant & $-0.025[0.020]^{* *}$ & $-0.038[0.036]$ \\
$\omega$ & $\left.0.041^{* 0.012}\right]^{* *}$ & $0.097[0.033]^{* *}$ \\
$\alpha(1)$ & $0.086[0.012]^{* *}$ & $0.066[0.015]^{* *}$ \\
$\beta(1)$ & $0.901[0.013]^{* *}$ & $0.895[0.022]^{* *}$ \\
$d f$ & $5.609[0.568]^{* *}$ & $7.033[1.313]^{* *}$ \\
$\mathrm{Q}(5) 1 /$ & $1.528^{*}$ & 4.642 \\
$\mathrm{Q}(5) 2 /$ & $1.978^{*}$ & 5.281 \\
Sign bias test & 1.118 & 1.578 \\
Negative size bias test & 1.602 & 0.173 \\
Positive size bias test & $2.738^{* *}$ & $2.753 * *$ \\
Joint test & $12.204^{* *}$ & 7.695 \\
\hline
\end{tabular}

Note:

1/ The Ljung-Box Q test applied to standardized residuals.

2/ The Ljung-Box Q test applied to squared standardized residuals.

The numbers in ( ) and [ ] refer to lag lengths and standard deviations. 
Table 3. ARMA-FIGARCH Estimates

\begin{tabular}{l|cc}
\hline & $1990 / 1 / 1-2002 / 8 / 8$ & $1997 / 1 / 1-2002 / 8 / 8$ \\
\hline Constant & $-0.022[0.020]$ & $-0.036[0.036]$ \\
$\omega$ & $0.080[0.027]^{* *}$ & $0.177[0.105]$ \\
$\mathrm{d}$ (hat) & $0.543[0.092]^{* *}$ & $0.356[0.102]^{* *}$ \\
$\beta$ & $0.616[0.087]^{* *}$ & $0.475[0.156]^{* *}$ \\
$\phi$ & $0.118[0.051]^{*}$ & $0.127[0.096]$ \\
$d f$ & $5.601[0.551]^{* *}$ & $6.818[1.266]^{* *}$ \\
$\mathrm{Q}(5) 1 /$ & 1.109 & 5.087 \\
$\mathrm{Q}(5) 2 /$ & 0.644 & 1.852 \\
Sign bias test & 1.192 & 1.382 \\
Negative size bias test & $2.383^{*}$ & 1.103 \\
Positive size bias test & $2.09^{*}$ & 1.681 \\
Joint test & $12.476^{* *}$ & 4.057 \\
\hline
\end{tabular}

Note:

See Table 2 . 
Table 4. ARFIMA-FIGARCH Estimates

\begin{tabular}{l|cc}
\hline & $1990 / 1 / 1-2002 / 8 / 8$ & $1997 / 1 / 1-2002 / 8 / 8$ \\
\hline Constant & $-0.019[0.016]^{* *}$ & $-0.033[0.026]$ \\
$\mathrm{d}$ & $-0.034[0.013]^{* *}$ & $-0.050[0.019]^{* *}$ \\
$\omega$ & $0.081[0.027]^{* *}$ & $0.179[0.107]$ \\
$\mathrm{d}($ hat) & $0.544[0.093]^{* *}$ & $0.354[0.101]^{* *}$ \\
$\beta$ & $0.616[0.089]^{* *}$ & $0.471[0.158]^{* *}$ \\
$\phi$ & $0.109[0.050]^{*}$ & $0.121[0.097]$ \\
$d f$ & $5.530[0.539]^{* *}$ & $6.808[1.262]^{* *}$ \\
$\mathrm{Q}(5) 1 /$ & $2.471^{*}$ & 0.682 \\
$\mathrm{Q}(5) 2 /$ & 0.579 & 1.708 \\
Sign bias test & 0.68 & 0.017 \\
Negative size bias test & $2.147 *$ & 0.438 \\
Positive size bias test & 1.737 & 1.105 \\
Joint test & $12.602 * *$ & 2.833 \\
\hline
\end{tabular}

Note:

See Table 2. 
Figure 1. Daily Nikkei 225 from 1990/1/1-2002/8/8

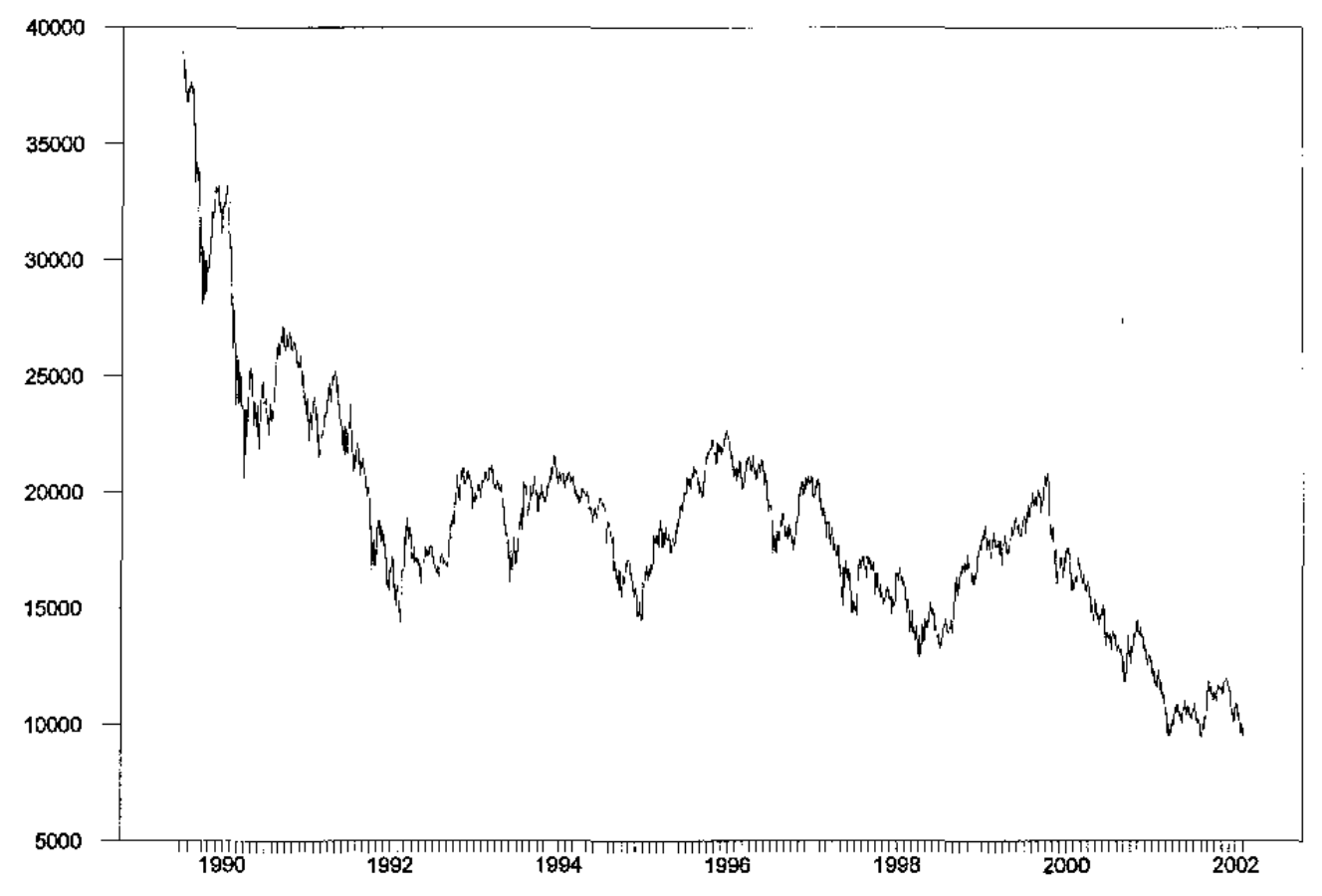


Figure 2. Monthly Nikkei 225 from $1992 / 1$ to $2002 / 8$

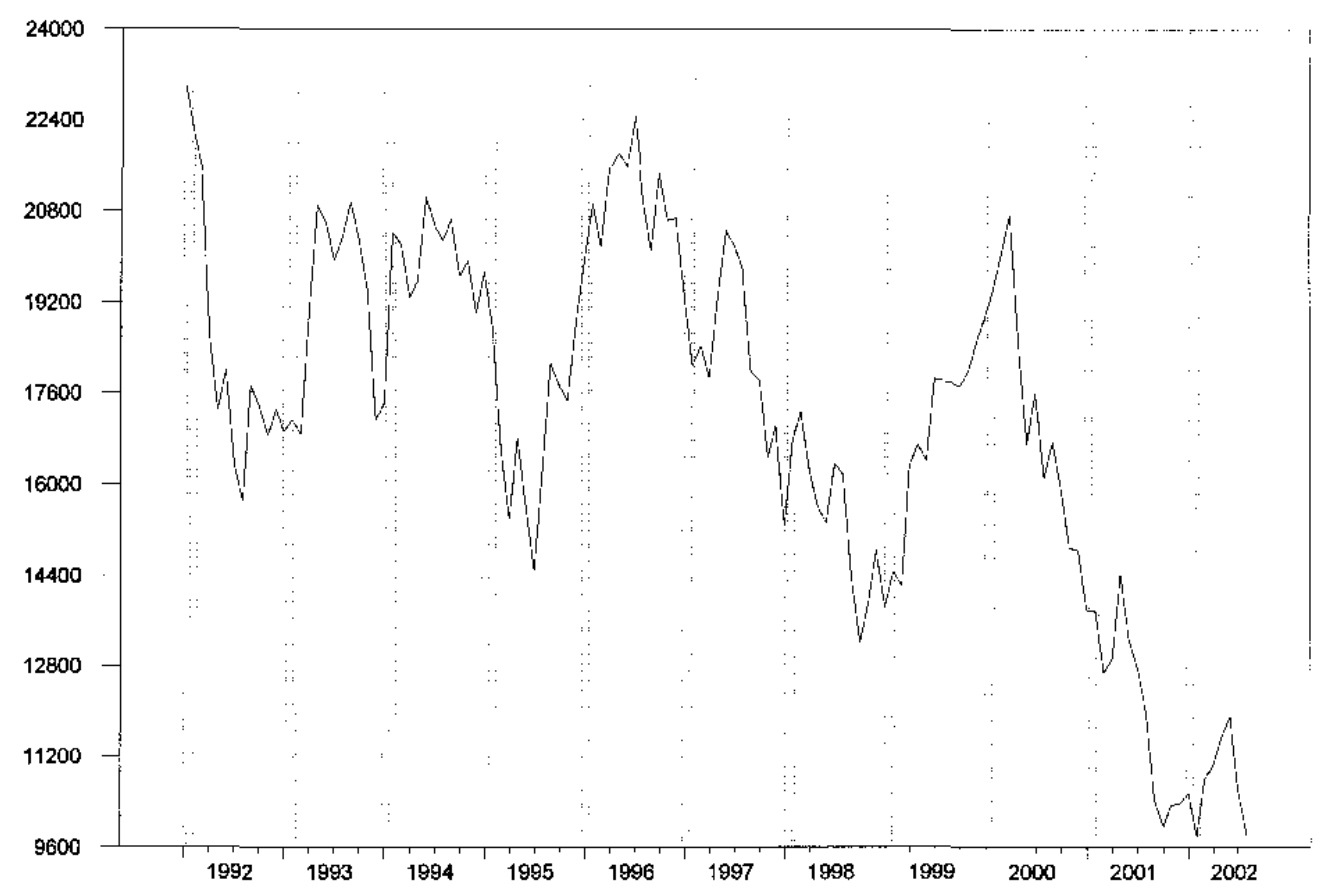

Note: Figures for January and February are shaded. 